\title{
Alzheimer's Disease and HLA-A2: Linking Neurodegenerative to Immune Processes through an In Silico Approach
}

\author{
Ricardo A. Cifuentes and Juan Murillo-Rojas \\ Area of Basic Sciences, Faculty of Medicine, Universidad Militar Nueva Granada, Bogotá, Colombia \\ Correspondence should be addressed to Ricardo A. Cifuentes; ricardo.cifuentesgarcia@gmail.com
}

Received 22 January 2014; Accepted 8 July 2014; Published 17 August 2014

Academic Editor: Francesco Pappalardo

Copyright ( 2014 R. A. Cifuentes and J. Murillo-Rojas. This is an open access article distributed under the Creative Commons Attribution License, which permits unrestricted use, distribution, and reproduction in any medium, provided the original work is properly cited.

\begin{abstract}
There is a controversial relationship between HLA-A2 and Alzheimer's disease (AD). It has been suggested a modifier effect on the risk that depends on genetic loadings. Thus, the aims of this study were to evaluate this relationship and to reveal genes associated with both concepts the HLA-A gene and AD. Consequently, we did first a classical systematic review and a meta-analysis of casecontrol studies. Next, by means of an in silico approach, we used experimental knowledge of protein-protein interactions to evaluate the top ranked genes shared by both concepts, previously found through text mining. The meta-analysis did not show a significant pooled OR (1.11, 95\% CI: 0.98 to 1.24 in Caucasians), in spite of the fact that four of the included studies had a significant OR $>1$ and none of them a significant $\mathrm{OR}<1$. In contrast, the in silico approach retrieved nonrandomly shared genes by both concepts $(P$ $=0.02$ ), which additionally encode truly interacting proteins. The network of proteins encoded by APP, ICAM-1, ITGB2, ITGAL, SELP, SELL, IL2, IL1B, CD4, and CD8A linked immune to neurodegenerative processes and highlighted the potential roles in AD pathogenesis of endothelial regulation, infectious diseases, specific antigen presentation, and HLA-A2 in maintaining synapses.
\end{abstract}

\section{Introduction}

Alzheimer's disease (AD) is a neurodegenerative process of the central nervous system (CNS) that is clinically characterized by an impairment of memory and other cognitive functions [1]. It is recognized as a multifactorial illness with both genetic and nongenetic causes. There have been identified four major genes associated with inherited risk for $\mathrm{AD}$ : presenilin-1, presenilin-2, amyloid precursor protein (APP), and apolipoprotein E. Mutations in these genes cause dysregulation of amyloid precursor protein processing, and in particular of the handling of a proteolytic derivative termed beta-amyloid (Abeta) that ultimately causes neuronal dysfunction and death [2].

Some findings also suggest an immune involvement in $\mathrm{AD}$. Telomere length of $\mathrm{T}$ cells has been inversely correlated with cognitive performance impairment, apoptosis, serum levels of TNF- $\alpha$, and the proportion of $\mathrm{CD} 8^{+} \mathrm{T}$ cells lacking expression of the CD28 costimulatory molecule [3]. There are augmented levels of $\mathrm{CD} 8^{+} \mathrm{T}$ memory cells, down regulation of $\mathrm{CD} 8$ receptors, and increased reactivity of $\mathrm{CD} 4^{+}$and $\mathrm{CD} 8^{+}$ T-cells [4]. With regard to disease stages, there have been reported alterations in subsets of $\mathrm{CD} 4^{+}$cells in patients with mild $\mathrm{AD}$, with decreased percentages of naive cells, elevated memory cells, and increased proportions of $\mathrm{CD} 4^{+}$cells lacking CD28. T potentially regulatory cells, $\mathrm{CD} 4^{+} \mathrm{CD} 25^{\text {thigh }}$, with a naive phenotype are also reduced in $\mathrm{AD}$ patients [5]. It has been observed in patients of severe stage that there is a significant TNF- $\alpha$ increase in serum as well as a significant decrease in $\mathrm{CD}^{+}{ }^{+}$lymphocytes [6].

Epidemiological data suggest that some determinants of $\mathrm{AD}$ might reside in genes from the human leukocyte antigen (HLA) that regulate immune inflammatory responses [7]. It has been described the association of $\mathrm{AD}$ with both HLA-B7 and HLA-A2 [1]. Some authors have also found increased frequency of HLA-A $* 01$ and HLA-DRB1 $* 03$ alleles and decreased frequency of HLA-DRB $* 09$ in late-onset AD cases $[8,9]$. But these associations have shown no consistency among different ethnic groups [1]; nearly every positive result has been followed by several studies that have failed 
to replicate it or that have contradicted it [7]. In the case of HLA-DRB1 $* 03$ and its linked TNF- $\alpha$ 2-1-2 haplotype (-308/ A, $-238 / \mathrm{G}$ and TNF-a2 polymorphisms), it has been described a protective effect against $\mathrm{AD}$ [10], contrary to the effect of the HLA-DRB $1 * 03$ allele described above. Even more, some researchers have indicated that there is no compelling evidence of a strong, direct association between $\mathrm{AD}$ and any HLA class I or II allele [11]. Consequently, it has been suggested that there is a modifier effect on the risk that depends on genetic loadings and further analysis, considering both HLA and non-HLA genes, are therefore necessary $[7,10]$.

However, there is accumulated evidence that suggests the involvement of the HLA-A gene in the pathogenesis of AD. A meta-analysis of all studies available until the 2000th year supported previous evidence of an excess of HLA-A2 in AD [12]. More recently, it has been observed that HLA-A2 and APOE4 independently reduced the age at onset of AD through an effect that seems to be additive in a population from China [13] and that A2 homozygotes had an earlier onset of $\mathrm{AD}$ in a population from North-America [14]. With this panorama, the aims of this study were to evaluate the current evidence of the association between HLA-A2 and AD and reveal genes that can influence the relationship between HLA-A and AD, thus assisting to point out pathogenic pathways related to $\mathrm{AD}$. Our analysis was made by means of a meta-analysis of case-control studies that evaluated this association, and by using experimental knowledge of proteinprotein interactions to evaluate the top ranked genes that were shared by the concepts HLA-A and AD, which had previously been found through a text mining approach of the biomedical literature.

\section{Materials and Methods}

2.1. Search Strategy and Selection Criteria. A systematic review of electronic databases (PubMed, EMBASE) was done independently by two researchers. The final date for inclusion was June, 2013. The search strategy used MeSH terms and text words: "Alzheimer disease," "Alzheimer's disease," "Alzheimer," and "HLA." No other criteria were taken into account. The inclusion criteria were the following: (1) AD diagnosis established by using the National Institute of Neurological and Communicative Disorders and Stroke and the Alzheimer's Disease and Related Disorders Association (NINCDS-ADRDA), The Consortium to Establish a Registry for Alzheimer's Disease (CERAD) or the Diagnostic and Statistical Manual (DSM) criteria; (2) If AD diagnosis criteria mentioned in numeral 1 were not used, the article must mention that there was histopathological confirmation or that other causes of dementia were clinically excluded in the patients from the $\mathrm{AD}$ cohort; (3) indication in the title or in the abstract that a relationship between HLA and AD was evaluated; (4) case-control study design; (5) publication of sufficient original data on the HLA-A2 prevalence in cases and in controls to calculate reliable odds ratios (OR) [15]; (6) etiology of cases not related to the four major genes described in $\mathrm{AD}$ [2]; and (7) manuscript's publication in a peer-reviewed journal as a full paper.
2.2. Data Extraction and Meta-Analysis. The data collected from each study were as follows: first author and the year of study, country, the number of cases and controls typified as HLA-A2 or with the alternative classification of HLA-A. Calculations were done for each ethnic origin by using the Catmap package at $\mathrm{R}$ software [16] as previously described [15]. Briefly, OR were grouped by weighing individual OR by the inverse of their variance. Thus, the final effect OR and the $95 \%$ confidence interval $(95 \% \mathrm{CI})$ were obtained by means of both random- and fixed-effects models. The fixed-effects model was used when the random-effects variance was less than or equal to zero and there was no heterogeneity, defined as $P<0.10$ by the Cochran's $(Q)$ test; otherwise, the randomeffects model was chosen. Publication bias was evaluated by a sensitivity analysis.

2.3. Text Mining Approach. To find out the genetic similarity of the "HLA-A" and "Alzheimer's disease" concepts, we used the Anni software [17] because it uses the concept profile methodology that has proven to be effective in finding information in the form of associations in the biological domain [18], as previously described [19]. Briefly, we first mapped those concepts in the thesaurus of the software and built the concept profile for each one. These profiles corresponded to the weighted list made by all the genes mentioned in MedLine, so they were called genetic concept profiles (GCPs). To do this, we selected the 25.010 genes that belong to human beings from the thesaurus in Anni, and, then, we mined all the MedLine records that contained these genes in their text.

Next, we matched these two GCPs and analyzed the similarities between them. For this purpose, we obtained a cohesion score (CS) by using as an inclusive filter for matching the described 25.010 genes. To interpret the cohesion score we used a $P$ value that gives the probability that the same CS or higher would be found in a random group of the same size. This $P$ value was obtained by using the default parameter in Anni of 200 iterations. The contribution of each gene in the profile to the similarity between both GCPs was assessed in terms of percentage. The MedLine records that support a contribution higher than $0.1 \%$ to the similarity between GCPs were reviewed to verify that true genes, or the proteins they encode, were associated to the concepts "HLA-A" or "Alzheimer's disease." Associations with ambiguous terms were eliminated.

2.4. Evaluation of Shared Genes by a Protein-Protein Interaction Network. To analyze which of the proteins encoded by the genes with the highest contribution to the similarity between GCPs truly interact, a network analysis was done with the genes that contributed at least $0.1 \%$ to the CS. For this purpose, the software, Genes2networks, was employed because it provides a reference network of experimentally known protein-protein interactions [20]. Then, in order to find tightly connected proteins, the settings that were used to build the network were (1) no filter for minimum number of references, (2) the maximum links per reference were four, (3) a maximum pathway length of two, and (4) a significant 
TABLE 1: Description of the included articles.

\begin{tabular}{|c|c|c|c|c|c|}
\hline Study & Country/population & Cases/controls & Typing/technique & Diagnostic criteria & Reference \\
\hline Henschke et al., 1978 & Canada & $34 / 239$ & Lymphotoxicity & $\begin{array}{l}\text { Exclusion of other } \\
\text { causes of dementia }\end{array}$ & {$[21]$} \\
\hline Sulkava et al., 1980 & Finland & $32 / 35$ & Lymphotoxicity & $\begin{array}{l}\text { Exclusion of other } \\
\text { causes of dementia }\end{array}$ & {$[22]$} \\
\hline Wilcox et al., 1980 & United Kingdom & $18 / 342$ & Lymphotoxicity & $\begin{array}{l}\text { Exclusion of other } \\
\text { causes of dementia }\end{array}$ & {$[23]$} \\
\hline Whalley et al., 1980 & United Kingdom & $14 / 64$ & Lymphotoxicity & $\begin{array}{l}\text { Exclusion of other } \\
\text { causes of dementia }\end{array}$ & {$[24]$} \\
\hline Majsky and Vojtechovsky, 1983 & Czechoslovakia & $38 / 301$ & Lymphotoxicity & $\begin{array}{l}\text { Exclusion of other } \\
\text { causes of } \\
\text { dementia-Haschinsky }\end{array}$ & [25] \\
\hline Reed et al., 1983 & United States & $44 / 100$ & Lymphotoxicity & $\begin{array}{l}\text { Exclusion of other } \\
\text { causes of dementia }\end{array}$ & [26] \\
\hline Reisner et al., 1983 & United States & $52 / 305$ & Amos modified method & $\begin{array}{l}\text { Histopathological } \\
\text { confirmation }\end{array}$ & {$[27]$} \\
\hline Renvoize, 1984 & United Kingdom & $124 / 458$ & Lympho-toxicity & $\begin{array}{l}\text { Exclusion of other } \\
\text { causes of dementia }\end{array}$ & [28] \\
\hline Endo et al., 1986 & Japan & $122 / 66$ & Lympho-toxicity & DSM III & {$[36]$} \\
\hline Small and Matsuyama, 1986 & United States & $36 / 25$ & Lympho-toxicity & DSM III & {$[29]$} \\
\hline Payami et al., 1991 & United States & $54 / 263$ & Lymphotoxicity & NINCDS-ADRDA & {$[30]$} \\
\hline Middleton et al., 1999 & United Kingdom & $95 / 45$ & PCR SSOP & $\begin{array}{l}\text { Histopathological } \\
\text { confirmation }\end{array}$ & {$[31]$} \\
\hline Small et al., 1999 & United States & $479 / 233$ & PCR SSP & NINCDS-ADRDA & {$[32]$} \\
\hline Harris et al., 2000 & United Kingdom & $178 / 161$ & PCR SSP & NINCDS-ADRDA & {$[12]$} \\
\hline Lehmann et al., 2001 & United Kingdom & $55 / 73$ & PCR SSP & $\begin{array}{l}\text { Histopathological } \\
\text { confirmation CERAD }\end{array}$ & {$[11]$} \\
\hline Araria-Goumidi et al., 2002 & France & $451 / 477$ & Duplex-PCR & $\begin{array}{l}\text { DSM III and } \\
\text { NINCDS-ADRDA }\end{array}$ & [33] \\
\hline Listì et al., 2006 & Italy & $460 / 266$ & PCR SSP & NINCDS-ADRDA & {$[34]$} \\
\hline Ma et al., 2008 & China & $160 / 167$ & SBT & NINCDS-ADRDA & {$[13]$} \\
\hline Guerini et al., 2009 & Italy & $173 / 258$ & PCR SSP & NINCDS-ADRDA & {$[35]$} \\
\hline
\end{tabular}

AD: Alzheimer's disease, PCR SSOP: Polymerase chain reaction and sequence specific oligonucleotide probe, PCR SSP: Polymerase chain reaction and sequence specific primers, SBT: Sequence based typing, DSM: Diagnostic and Statistical Manual, NINCDS-ADRDA: National Institute of Neurological and Communicative Disorders and Stroke and the Alzheimer's Disease and Related Disorders Association, CERAD: Consortium to Establish a Registry for Alzheimer's Disease.

$z$-score of 2.5 of the intermediate nodes, which was calculated through a binomial proportions test, as previously described [19].

\section{Results}

From Europe, North-America and Asia, nineteen studies with data from case-control studies (2619 cases and 3878 controls) fitted the selection criteria; detailed information on the 185 articles that were excluded is given in the supplementary Table S1 in the Supplementary Material available online at http://dx.doi.org/10.1155/2014/791238. 17 of the included studies were from Caucasians $[11,12,21-35]$ and 2 from Asians $[13,36]$; see Table 1. Regarding the meta-analysis, the HLAA2 did not have a specific behavior of risk or of protection with a pooled OR of $1.11,95 \% \mathrm{CI}$ : 0.98 to 1.24 ( $Q P$ value 0.02 ).
None of the articles included in the meta-analysis showed a significant OR lesser than one, but in contrast four studies showed a significant OR higher than one. In the same line, exclusion of one study by means of the sensitivity analysis led in some cases to significant risk behavior of the HLA-A2 but never to a significant protective behavior (Figure 1).

As it was recognized the cross-reactivity of the HLA-A2 antigen with HLA-A28, and that sera containing antibodies against A2 and A28 supertypic determinants are frequently found [37], we did a meta-analysis in Caucasians with the 8 studies that only used molecular techniques [11-13, 31-35]; see Table 1. The model showed similar unspecific results with a pooled OR of 1.03, 95\%CI: 0.9 to 1.19 (QP value 0.03 ). With regard to the studies from Asia, the model also showed a very unspecific pooled OR than can be found between 0.84 and $2.16(Q P$ value 0.19$)$. 


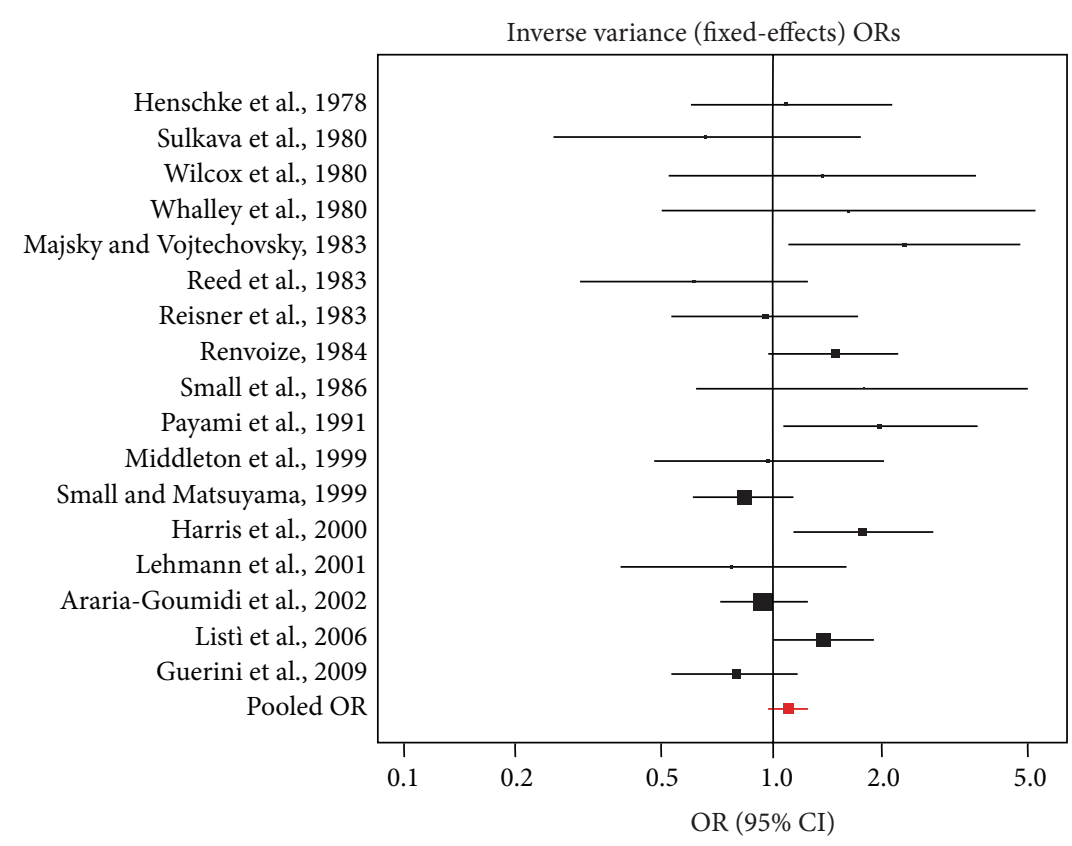

(a)

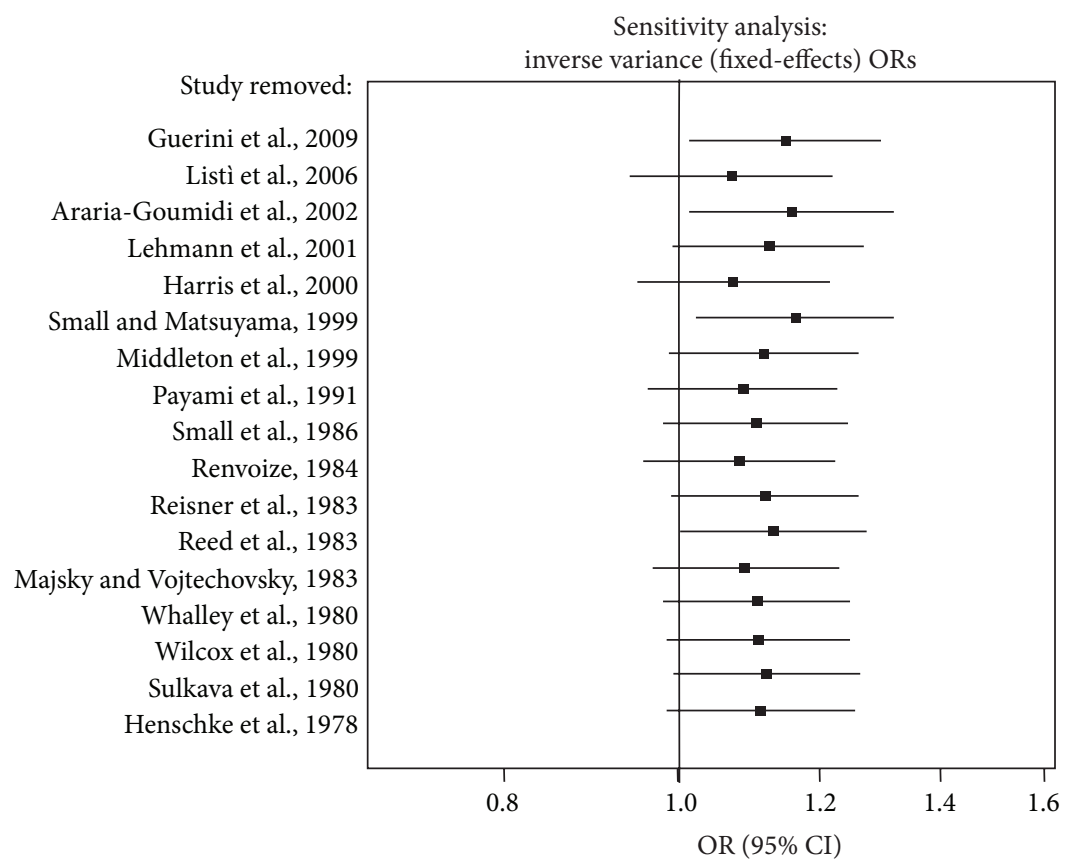

(b)

Figure 1: Forest plots of studies that relate HLA-A2 and AD. (a) Shows the effect summary OR (pooled OR) that takes into account all the studies. (b) Shows the pooled OR when each one of the studies was removed (sensitivity analysis).

Contrary to the nonconclusive results of the meta-analysis, the GCPs from both concepts AD and HLA-A were, not at random, genetically similar (CS $P$ value 0.02 ). In addition to the $H L A-A, 20$ genes had a contribution higher than $0.1 \%$ to this similarity. As it was expected the weights of the genes involved in neuron remodeling and differentiation such as $A P P$ and APLP2 were higher in the GCP of AD and the weights of the genes involved in immunity such as HLADRB1 were higher in the GCP of HLA-A (Table 2).

Regarding the interaction analysis, proteins encoded from 10 of the 21 genes used as input were kept in the network, (Figure 2). Some genes shared by HLA-A and AD such as APLP2, HLA-DRB1, and HFE did not appear in the network despite their studied association with AD and/or HLA-A2 


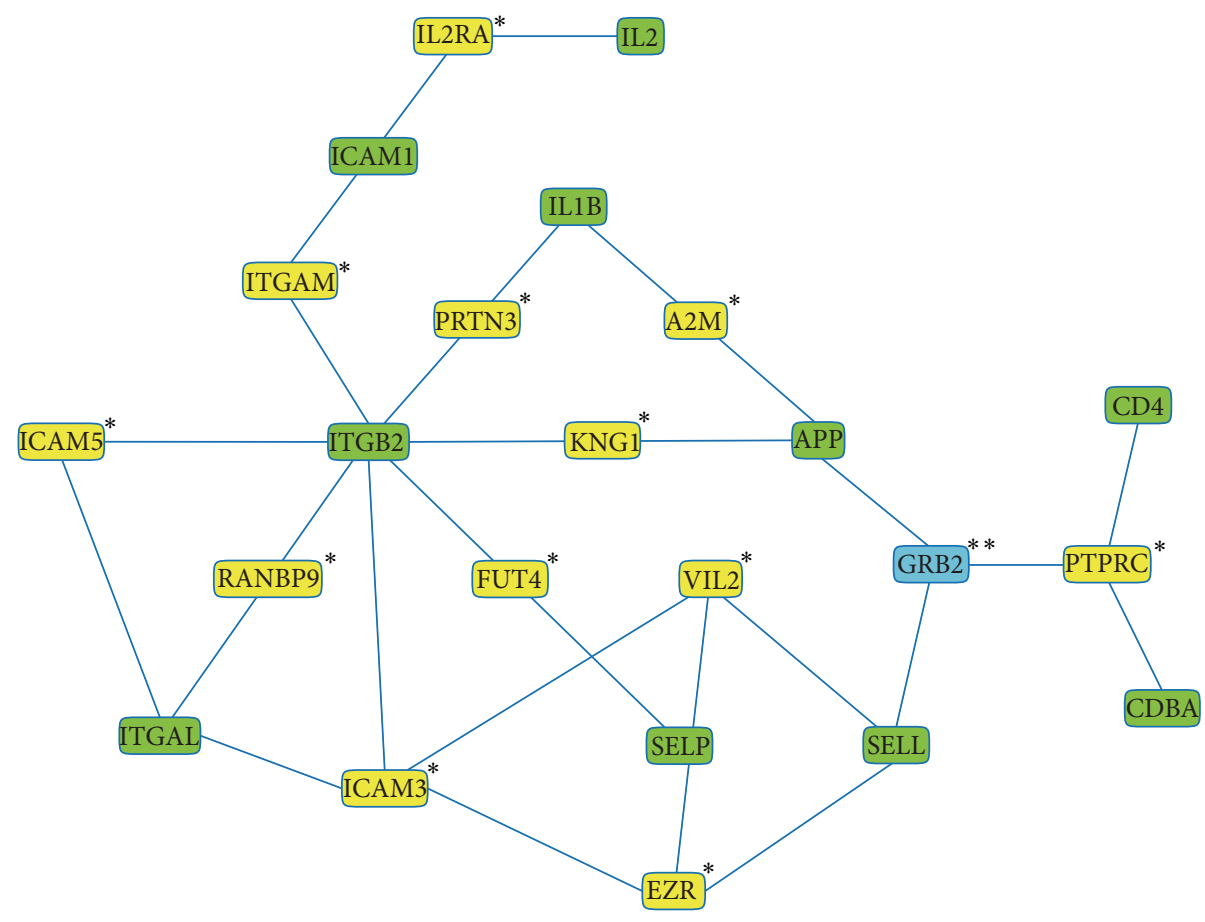

FIGURE 2: Interaction network of the proteins encoded by genes that contribute at least $0.1 \%$ to the cohesion score between HLA-A and AD. The nodes correspond to proteins encoded by the seed genes, to significant intermediary ones (indicated by one asterisk) and to a nonsignificant intermediary one (indicated by two asterisks).

TABLE 2: Genes with a contribution higher than $0.1 \%$ to the similarity between AD and HLA-A.

\begin{tabular}{|c|c|c|c|}
\hline Gene & Percentage & Weight in $\mathrm{AD}$ & Weight in HLA-A \\
\hline$H L A-A$ & 38.870 & $1.257 E-6$ & $3.990 E-2$ \\
\hline APLP2 & 21.170 & $4.900 E-3$ & $5.546 E-6$ \\
\hline$A P P$ & 17.115 & $7.000 E-3$ & $3.176 E-6$ \\
\hline$H L A-D R B 1$ & 5.576 & $3.333 E-6$ & $2.200 E-3$ \\
\hline$C D 8 A$ & 3.116 & $1.434 E-5$ & $3.000 E-4$ \\
\hline ICAM1 & 2.115 & $5.694 E-6$ & $5.000 E-4$ \\
\hline$H L A-B$ & 1.904 & $1.067 E-6$ & $2.300 E-3$ \\
\hline$H L A-C$ & 1.721 & $1.472 E-6$ & $1.500 E-3$ \\
\hline CD4 & 0.611 & $2.812 E-5$ & $2.807 E-5$ \\
\hline IFNG & 0.391 & $6.326 E-6$ & $7.995 E-5$ \\
\hline HFE & 0.223 & $2.891 E-6$ & $9.967 E-5$ \\
\hline$I L 1 B$ & 0.176 & $2.309 E-5$ & $9.881 E-6$ \\
\hline IL2 & 0.170 & $8.815 E-6$ & $2.494 E-5$ \\
\hline TYR & 0.165 & $2.515 E-6$ & $8.474 E-5$ \\
\hline$W T 1$ & 0.147 & $1.599 E-6$ & $1.000 E-4$ \\
\hline SELL & 0.138 & $1.748 E-6$ & $1.000 E-4$ \\
\hline ITGB2 & 0.135 & $4.105 E-6$ & $4.252 E-5$ \\
\hline$I T G A L$ & 0.128 & $2.750 E-6$ & $6.013 E-5$ \\
\hline CD80 & 0.124 & $4.628 E-6$ & $3.470 E-5$ \\
\hline CD86 & 0.123 & $3.332 E-6$ & $4.798 E-5$ \\
\hline SELP & 0.113 & $2.683 E-6$ & $5.478 E-5$ \\
\hline
\end{tabular}

Cohesion score $P$ value 0.02 . 
TABLE 3: Significance of intermediates sorted by $z$-score.

\begin{tabular}{|c|c|c|c|c|c|}
\hline Node name & Links & Links in background & Links to seed & Links in subnetwork & $z$-score \\
\hline FUT4 & 3 & 11429 & 2 & 29 & 22.86 \\
\hline ICAM5 & 4 & 11429 & 2 & 29 & 19.77 \\
\hline PRTN3 & 9 & 11429 & 2 & 29 & 13.10 \\
\hline IL2RA & 22 & 11429 & 3 & 29 & 12.47 \\
\hline ICAM3 & 10 & 11429 & 2 & 29 & 12.41 \\
\hline VIL2 & 32 & 11429 & 3 & 29 & 10.25 \\
\hline ITGAM & 15 & 11429 & 2 & 29 & 10.06 \\
\hline EZR & 34 & 11429 & 3 & 29 & 9.93 \\
\hline KNG1 & 22 & 11429 & 2 & 29 & 8.23 \\
\hline RANBP9 & 22 & 11429 & 2 & 29 & 8.23 \\
\hline $\mathrm{A} 2 \mathrm{M}$ & 24 & 11429 & 2 & 29 & 7.86 \\
\hline PTPRC & 35 & 11429 & 2 & 29 & 6.42 \\
\hline GRB2 & 196 & 11429 & 2 & 29 & 2.13 \\
\hline
\end{tabular}

$[8,38,39]$ and even the linkage disequilibrium with the HLA-A gene [40]. This could have been because of the strict threshold, a maximum pathway length of two, established to avoid weak interactions. Furthermore, the network had 13 intermediary nodes, 12 significant with a $z$-score above the cutoff of 2.5 (Table 3 ), thus indicating that the seed genes encode proteins that had strong and specific interactions.

In the graph, we found out two subnetworks (Figure 2): The first was made up of APP (involved in remodeling, differentiation, and apoptosis of neurons), ICAM1, ITGB2, ITGAL, SELP and SELL (involved in leukocyte adhesion, rolling over vascular surfaces, and transendotelial migration), and IL2 and IL1B (involved in T-cell proliferation, activation, and inflammation) and the second subnetwork was made up of CD4 and CD8A (involved in HLA classes I and II antigen presentation). These two subnetworks were connected by the growth factor receptor-bound protein (GRB2), the unique intermediate node that had a nonsignificant $z$-score due to low specificity because of its many links (Table 3 ), in other words, because it is a molecule involved in many cellular processes [41].

\section{Discussion}

Despite having new studies with big samples and homogeneous criteria for inclusion of $\mathrm{AD}$ patients (i.e., NINCDSADRDA) compared to the meta-analysis that associated HLA-A2 and AD more than ten years ago [12], we did not find conclusive results by this classical approach. The HLA-A2 showed to be a mild risk factor of $\mathrm{AD}$ with significant results only in some populations, thus suggesting that there are processes that influence this relationship. In contrast, the in silico approach retrieved nonrandomly shared genes by the concepts of HLA-A and $\mathrm{AD}(P=0.02)$, that additionally encode truly interacting proteins. Proteins encoded by $A P P, I C A M-$ 1, ITGB2, ITGAL, SELP, SELL, IL2, IL1B, CD4, and CD8A interact and were statistically and experimentally related to both concepts: HLA-A and AD. The network of interacting proteins highlighted specific processes, thus assisting to point out relevant pathogenic pathways that linked immunity to AD. Immune processes such as leukocyte adhesion and transendothelial migration, peptide presentation, and Tcell activation and proliferation were linked to processes traditionally involved in the pathogenesis of $\mathrm{AD}$ such as remodeling and apoptosis of neurons.

The results of our meta-analysis point out the importance of finding out relevant gene networks than can influence the relationship between HLA-A and AD and are in the same line with a previous analysis of the HLA-B, another gene of the same complex genomic region. In Oxford, researchers from UK confirmed in 2006 the association between HLA-B7 and $\mathrm{AD}$, which was previously found in other people from the same city in 2001. However, this association was not found in populations from Cambridge, UK, and Montreal, Canada in spite the fact that all were of Caucasian origin. That is why, it was suggested a geographical specificity that could be due to different interactions with other processes of environmental, genetic or epigenetic origin [42].

Regarding the highlighted processes by our analysis of gene networks, it has been observed alterations of endothelial regulation in AD. IL1A, IL1B, IL2, IL8, IFN $\gamma$, and TNF $\alpha$ have been found to be associated with senile plaques. Some of them, IL8 and IFN $\gamma$ were also significantly increased in plasma. Abnormal secretion of cytokines due to immune activation may impair the regulation of endothelial cells and induce altered pathways of adhesion molecules. There have been observed lower levels of P-selectin and L-selectin in AD and lowest in patients with the highest cognitive decline, thus leading to impaired regulation of both endothelial function and leukocyte migration [43]. With this landscape, infections at the level of the vasculature may be a key initiating factor in the pathogenesis of neurodegenerative diseases such as sporadic AD. Some observations have shown that C. pneumoniae infection stimulates transendothelial entry of monocytes through human brain endothelial cells (HBMECs). This entry 
is facilitated by the upregulation of VCAM-1 and ICAM-1 on HBMECs and a corresponding increase of ITGB2-ITGAL (LFA-1), VLA-4, and ITGB2-ITGAM (MAC-1) on monocytes [44].

Another important process is the antigen presentation as it has been demonstrated the highly immunogenic properties of one specific HLA class II allele in a model of AD. It was observed that Abeta was effectively cleared from the brain parenchyma and brain microglial activation was reduced in long-term therapeutic immunization of an $\mathrm{AD}$ mouse model bearing the DRB1*1501 allele [45]. Regarding to HLA-A2, it is a HLA class I protein that not only plays roles in the initiation of antigen receptor signaling, but is also expressed in neurons throughout the CNS. Neuronal HLA class I is upregulated after exposure to cytokines and functions as a mediator of synaptic plasticity during development of the visual system. Additional studies suggest that HLA class I may regulate the ability of neurons to maintain synapses. HLA class I mediated signaling has been studied, and it was observed that specifically HLA-A2 is substrate for the Alzheimer's diseaseassociated presenilin-1/gamma-secretase [46].

All in all, there is important evidence of the association between the described processes. A Genome Wide Association study found a significant single nucleotide polymorphism associated with $\mathrm{AD}$ within $G A B 2$, which encodes "GRB2-associated binding protein 2" (Gab2). Gab2 binds GRB2 that also binds tau, APP, presenilin-1, and presenilin2. Consequently, Gab2 could conceivably modulate APP processing and/or tau phosphorylation via its interaction with GRB2 [47]. Additionally, GRB2 is a known adapter with a recently described role in antigen receptor signaling as well as lymphocyte development [41].

\section{Conclusion}

Our review gives support to the immune involvement in AD. However, we not only find out a network of interacting proteins that links neurodegenerative to immune processes but that also gives hints for further research such as infectious diseases that alter the endothelial regulation as possible starting factor in $\mathrm{AD}$, the role of GRB2 as a molecule that links antigen presentation with neuronal processes or the HLAA2 role in the typical synaptic loss of AD. Thus, taking into account the described findings and the current overwhelming amount of data it seems highly advisable to combine in silico techniques with classical approaches such as systematic reviews or meta-analyses to find useful information.
Abbreviations
95\% CI: $95 \%$ confidence interval
Abeta: Beta-amyloid
AD: $\quad$ Alzheimer disease
APP: Amyloid precursor protein
CERAD: The Consortium to Establish a
Registry for Alzheimer's Disease
CNS: Central nervous system

$\begin{array}{ll}\text { CS: } & \text { Cohesion score } \\ \text { DSM: } & \text { Diagnostic and Statistical Manual } \\ \text { GCPs: } & \text { Genetic concept profiles } \\ \text { HBMECs: } & \text { Human brain endothelial cells } \\ \text { HLA: } & \text { Human leukocyte antigen } \\ \text { NINCDS-ADRDA: } & \text { National Institute of Neurological } \\ & \text { and Communicative Disorders and } \\ & \text { Stroke and the Alzheimer's Disease } \\ & \text { and Related Disorders Association } \\ \text { OR: } & \text { Odds ratio. }\end{array}$

\section{Conflict of Interests}

The authors declare no conflict of interests.

\section{Authors' Contribution}

R. A. Cifuentes performed the study design, data extraction, meta-analysis, text mining, network analysis, and redaction of the paper and J. Murillo-Rojas participated in the study design, data extraction, and supplementary tables.

\section{Acknowledgment}

This work was supported by the Universidad Militar Nueva Granada, Bogotá, Colombia.

\section{References}

[1] C. Alves, S. Veiga, T. Souza, M. B. Toralles, and A. L. Da SilvaBacellar, "The role of the human histocompatibility antigens in the pathogenesis of neurological disorders," Revista de Neurologia, vol. 44, no. 5, pp. 298-302, 2007.

[2] P. H. St George-Hyslop and A. Petit, "Molecular biology and genetics of Alzheimer's disease," Comptes Rendus Biologies, vol. 328, no. 2, pp. 119-130, 2005.

[3] L. A. Panossian, V. R. Porter, H. F. Valenzuela et al., "Telomere shortening in T cells correlates with Alzheimer's disease status," Neurobiology of Aging, vol. 24, no. 1, pp. 77-84, 2003.

[4] K. Schindowski, A. Eckert, J. Peters et al., "Increased Tcell reactivity and elevated levels of CD8+ memory T-cells in Alzheimer's disease-patients and T-cell hyporeactivity in an Alzheimer's disease-mouse model: Implications for immunotherapy," NeuroMolecular Medicine, vol. 9, no. 4, pp. 340-354, 2007.

[5] A. Larbi, G. Pawelec, J. M. Witkowski et al., "Dramatic shifts in circulating CD4 but not CD8 T cell subsets in mild Alzheimer's disease," Journal of Alzheimer's Disease, vol. 17, no. 1, pp. 91-103, 2009.

[6] K. Bonotis, E. Krikki, V. Holeva, C. Aggouridaki, V. Costa, and S. Baloyannis, "Systemic immune aberrations in Alzheimer's disease patients," Journal of Neuroimmunology, vol. 193, no. 1-2, pp. 183-187, 2008.

[7] G. Candore, C. R. Balistreri, G. Colonna-Romano, D. Lio, and C. Caruso, "Major histocompatibility complex and sporadic Alzheimer's disease: a critical reappraisal," Experimental Gerontology, vol. 39, no. 4, pp. 645-652, 2004. 
[8] D. Neill, M. D. Curran, D. Middleton et al., "Risk for Alzheimer's disease in older late-onset cases is associated with HLADRB1*03," Neuroscience Letters, vol. 275, no. 2, pp. 137-140, 1999.

[9] F. R. Guerini, C. Tinelli, E. Calabrese et al., "HLA-A*01 is associated with late onset of Alzheimer's disease in Italian patients," International Journal of Immunopathology and Pharmacology, vol. 22, no. 4, pp. 991-999, 2009.

[10] D. Culpan, S. H. MacGowan, J. M. Ford et al., “Tumour necrosis factor- $\alpha$ gene polymorphisms and Alzheimer's disease," Neuroscience Letters, vol. 350, no. 1, pp. 61-65, 2003.

[11] D. J. Lehmann, H. Wiebusch, S. E. Marshall et al., "HLA class I, II \& III genes in confirmed late-onset Alzheimer's disease," Neurobiology of Aging, vol. 22, no. 1, pp. 71-77, 2001.

[12] J. M. Harris, A. M. Cumming, N. Craddock, D. St Clair, and C. L. Lendon, "Human leucocyte antigen-A2 increases risk of Alzheimer's disease but does not affect age of onset in a Scottish population," Neuroscience Letters, vol. 294, no. 1, pp. 37-40, 2000 .

[13] S. L. Ma, N. L. S. Tang, C. W. C. Tam et al., "Association between HLA-A alleles and Alzheimer's disease in a Southern Chinese community," Dementia and Geriatric Cognitive Disorders, vol. 26, no. 5, pp. 391-397, 2008.

[14] S. Zareparsi, D. M. James, J. A. Kaye, T. D. Bird, G. D. Schellenberg, and H. Payami, "HLA-A2 homozygosity but not heterozygosity is associated with Alzheimer disease," Neurology, vol. 58, no. 6, pp. 973-975, 2002.

[15] R. A. Cifuentes, A. Rojas-Villarraga, and J.-M. Anaya, "Human leukocyte antigen class II and type 1 diabetes in Latin America: a combined meta-analysis of association and family-based studies," Human Immunology, vol. 72, no. 7, pp. 581-586, 2011.

[16] K. K. Nicodemus, "Catmap: case-control and TDT metaanalysis package," BMC Bioinformatics, vol. 9, article 130, 2008.

[17] R. Jelier, M. J. Schuemie, A. Veldhoven, L. C. J. Dorssers, G. Jenster, and J. A. Kors, "Anni 2.0: a multipurpose text-mining tool for the life sciences," Genome Biology, vol. 9, no. 6, article R96, 2008.

[18] R. Jelier, G. Jenster, L. C. J. Dorssers et al., “Text-derived concept profiles support assessment of DNA microarray data for acute myeloid leukemia and for androgen receptor stimulation," $B M C$ Bioinformatics, vol. 8, article 14, 2007.

[19] R. A. Cifuentes, D. Restrepo-Montoya, and J. Anaya, "The autoimmune tautology: an in silico approach," Autoimmune Diseases, vol. 2012, Article ID 792106, 2012.

[20] S. I. Berger, J. M. Posner, and A. Ma'ayan, "Genes2Networks: connecting lists of gene symbols using mammalian protein interactions databases," BMC Bioinformatics, vol. 8, article 372, 2007.

[21] P. J. Henschke, D. A. Bell, and R. D. T. Cape, "Alzheimer's disease and HLA," Tissue Antigens, vol. 12, no. 2, pp. 132-135, 1978.

[22] R. Sulkava, S. Koskimies, J. Wikstrom, and J. Palo, "HLA antigens in Alzheimers disease," Tissue Antigens, vol. 16, no. 2, pp. 191-194, 1980.

[23] C. B. Wilcox, E. A. Caspary, and P. O. Behan, "Histocompatibility antigens in Alzheimer's disease. A preliminary study," European Neurology, vol. 19, no. 4, pp. 262-265, 1980.

[24] L. J. Whalley, S. J. Urbaniak, C. Darg, J. F. Peutherer, and J. E. Christie, "Histocompatibility antigens and antibodies to viral and other antigens in Alzheimer pre-senile dementia," Acta Psychiatrica Scandinavica, vol. 61, no. 1, pp. 1-7, 1980.
[25] A. Majsky and M. Vojtechovsky, "Non-relationship between the HLA system and the senile form of Alzheimer's disease," Archiv fur Psychiatrie und Nervenkrankheiten, vol. 233, no. 5, pp. 381383, 1983.

[26] E. Reed, D. Thompson, R. Mayeaux, and N. Suciu Foca, "HLA antigens in Alzheimer's disease," Tissue Antigens, vol. 21, no. 2, pp. 164-167, 1983.

[27] E. Reisner, A. Heyman, T. Weinberg, D. Dawson, and E. Ciftan, "Lack of association between Alzheimer's disease and histocompatibility antigens," Tissue Antigens, vol. 21, no. 1, pp. 31-34, 1983.

[28] E. B. Renvoize, "An HLA and family study of Alzheimer's disease," Psychological Medicine, vol. 14, no. 3, pp. 515-520, 1984.

[29] G. W. Small and S. S. Matsuyama, "HLA-A2 as a possible marker for early-onset Alzheimer disease in men," Neurobiology of Aging, vol. 7, no. 3, pp. 211-214, 1986.

[30] H. Payami, J. Kaye, W. Becker, D. Norman, and P. Wetzsteon, "HLA-A2, or a closely linked gene, confers susceptibility to early-onset sporadic Alzheimer's disease in men," Neurology, vol. 41, no. 10, pp. 1544-1548, 1991.

[31] D. Middleton, H. Mawhinney, M. D. Curran et al., "Frequency of HLA-A and B alleles in early and late-onset Alzheimer's disease," Neuroscience Letters, vol. 262, no. 2, pp. 140-142, 1999.

[32] G. W. Small, W. K. Scott, S. Komo et al., "No association between the HLA-A2 allele and Alzheimer disease," Neurogenetics, vol. 2, no. 3, pp. 177-182, 1999.

[33] L. Araria-Goumidi, J. C. Lambert, D. Cottel, P. Amouyel, and M. C. Chartier-Harlin, "No association of the HLA-A2 allele with Alzheimer's disease," Neuroscience Letters, vol. 335, no. 2, pp. 7578, 2002.

[34] F. Listi, G. Candore, C. R. Balistreri et al., "Association between the HLA-A2 allele and Alzheimer disease," Rejuvenation Research, vol. 9, no. 1, pp. 99-101, 2006.

[35] F. R. Guerini, E. Calabrese, C. Agliardi et al., "Association study of the HLA-A2 allele in Italian Alzheimer disease patients," Neurobiology of Aging, vol. 30, no. 12, pp. 2082-2083, 2009.

[36] H. Endo, T. Yamamoto, and F. Kuzuya, "HLA system in senile dementia of Alzheimer type and multi-infarct dementia in Japan," Archives of Gerontology and Geriatrics, vol. 5, no. 1, pp. 51-56, 1986.

[37] M. A. Fernandez-Viña, M. Falco, Y. Sun, and P. Stastny, "DNA typing for HLA class I alleles: I. Subsets of HLA-A2 and of -A28," Human Immunology, vol. 33, no. 3, pp. 163-173, 1992.

[38] A. Tuli, M. Sharma, X. Wang et al., "Amyloid precursor-like protein 2 association with HLA class i molecules," Cancer Immunology, Immunotherapy, vol. 58, no. 9, pp. 1419-1431, 2009.

[39] A. P. Correia, J. P. Pinto, V. Dias, C. Mascarenhas, S. Almeida, and G. Porto, "CAT53 and HFE alleles in Alzheimer's disease: a putative protective role of the C282Y HFE mutation," Neuroscience Letters, vol. 457, no. 3, pp. 129-132, 2009.

[40] J. Vieira, C. S. Cardoso, J. Pinto et al., "A putative gene located at the MHC class I region around the D6S105 marker contributes to the setting of $\mathrm{CD}^{+}$T-lymphocyte numbers in humans," International Journal of Immunogenetics, vol. 34, no. 5, pp. 359367, 2007.

[41] I. K. Jang, J. Zhang, and H. Gu, "Grb2, a simple adapter with complex roles in lymphocyte development, function, and signaling," Immunological Reviews, vol. 232, no. 1, pp. 150-159, 2009. 
[42] D. J. Lehmann, M. C. N. M. Barnardo, S. Fuggle et al., "Replication of the association of HLA-B7 with Alzheimer's disease: a role for homozygosity?" Journal of Neuroinflammation, vol. 3, article 33, 2006.

[43] M. M. Corsi, F. Licastro, E. Porcellini et al., "Reduced plasma levels of P-selectin and L-selectin in a pilot study from Alzheimer disease: relationship with neuro-degeneration," Biogerontology, vol. 12, no. 5, pp. 451-454, 2011.

[44] A. MacIntyre, R. Abramov, C. J. Hammond et al., "Chlamydia pneumoniae infection promotes the transmigration of monocytes through human brain endothelial cells," Journal of Neuroscience Research, vol. 71, no. 5, pp. 740-750, 2003.

[45] V. Zota, A. Nemirovsky, R. Baron et al., "HLA-DR alleles in amyloid $\beta$-peptide autoimmunity: a highly immunogenic role for the DRB1*1501 allele," Journal of Immunology, vol. 183, no. 5, pp. 3522-3530, 2009.

[46] B. W. Carey, D. Y. Kim, and D. M. Kovacs, "Presenilin $/ \gamma$-secretase and $\alpha$-secretase-like peptidases cleave human MHC Class I proteins," Biochemical Journal, vol. 401, no. 1, pp. 121-127, 2007.

[47] L. Bertram and R. E. Tanzi, "Genome-wide association studies in Alzheimer's disease," Human Molecular Genetics, vol. 18, no. 2, pp. R137-R145, 2009. 

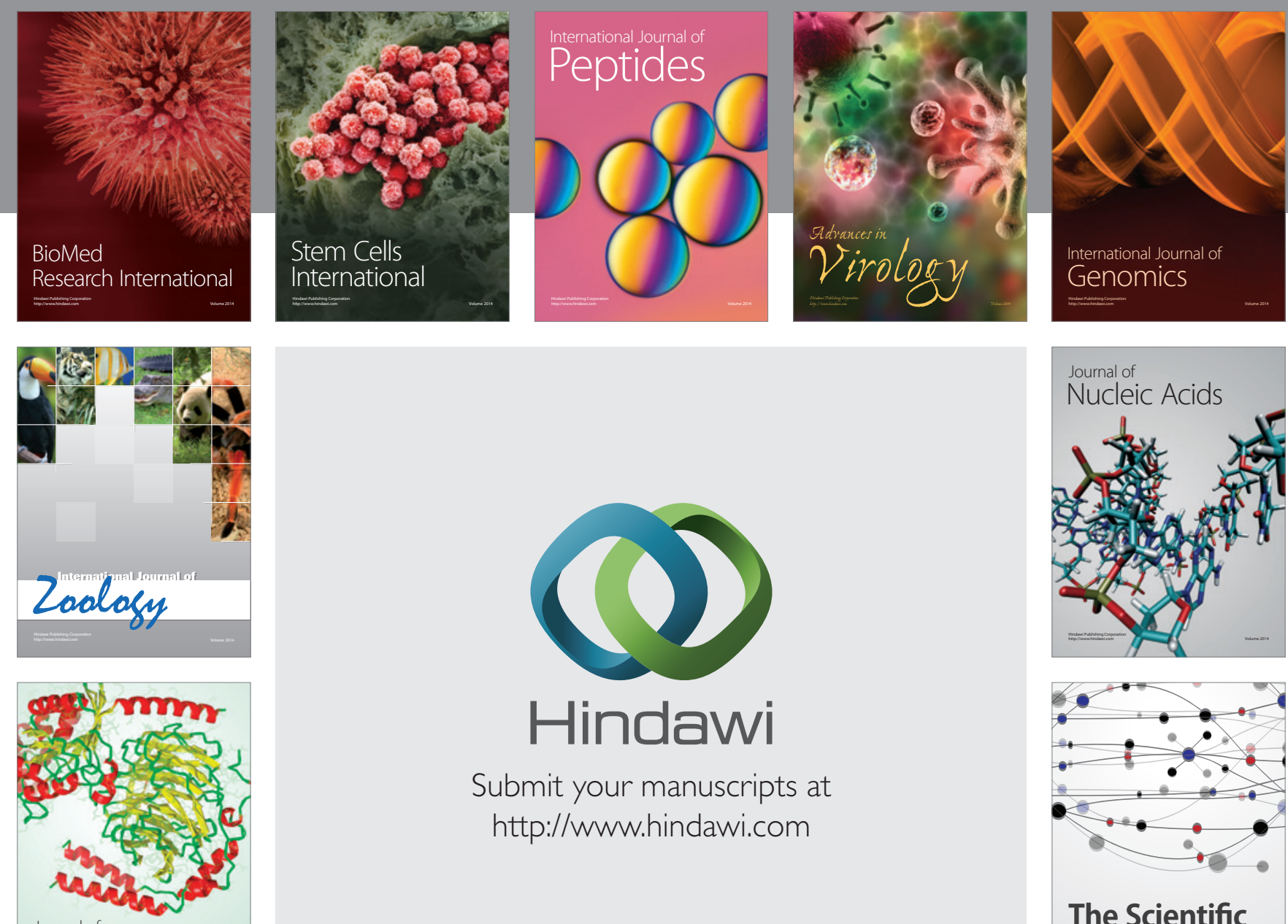

Submit your manuscripts at

http://www.hindawi.com

Journal of
Signal Transduction
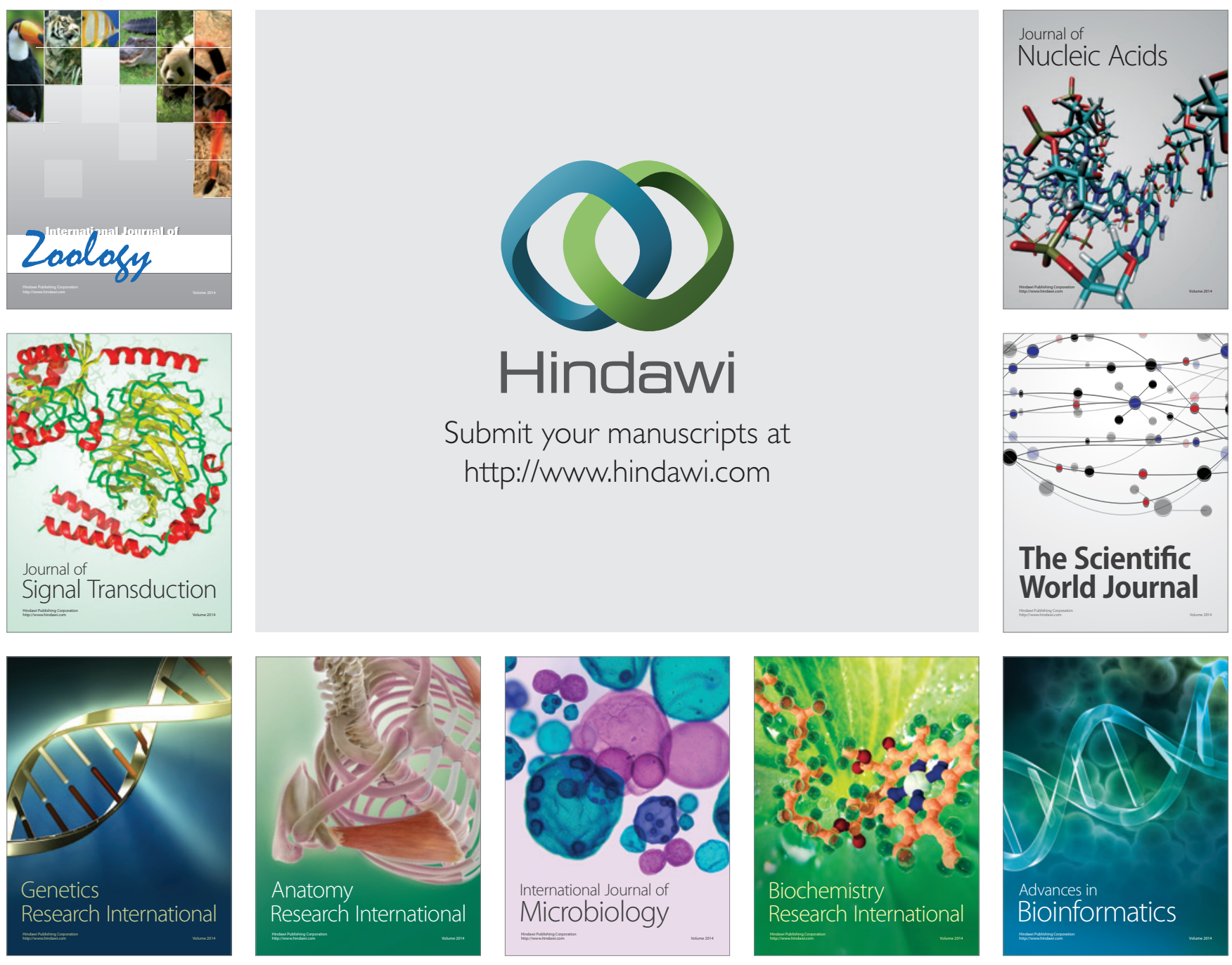

The Scientific World Journal
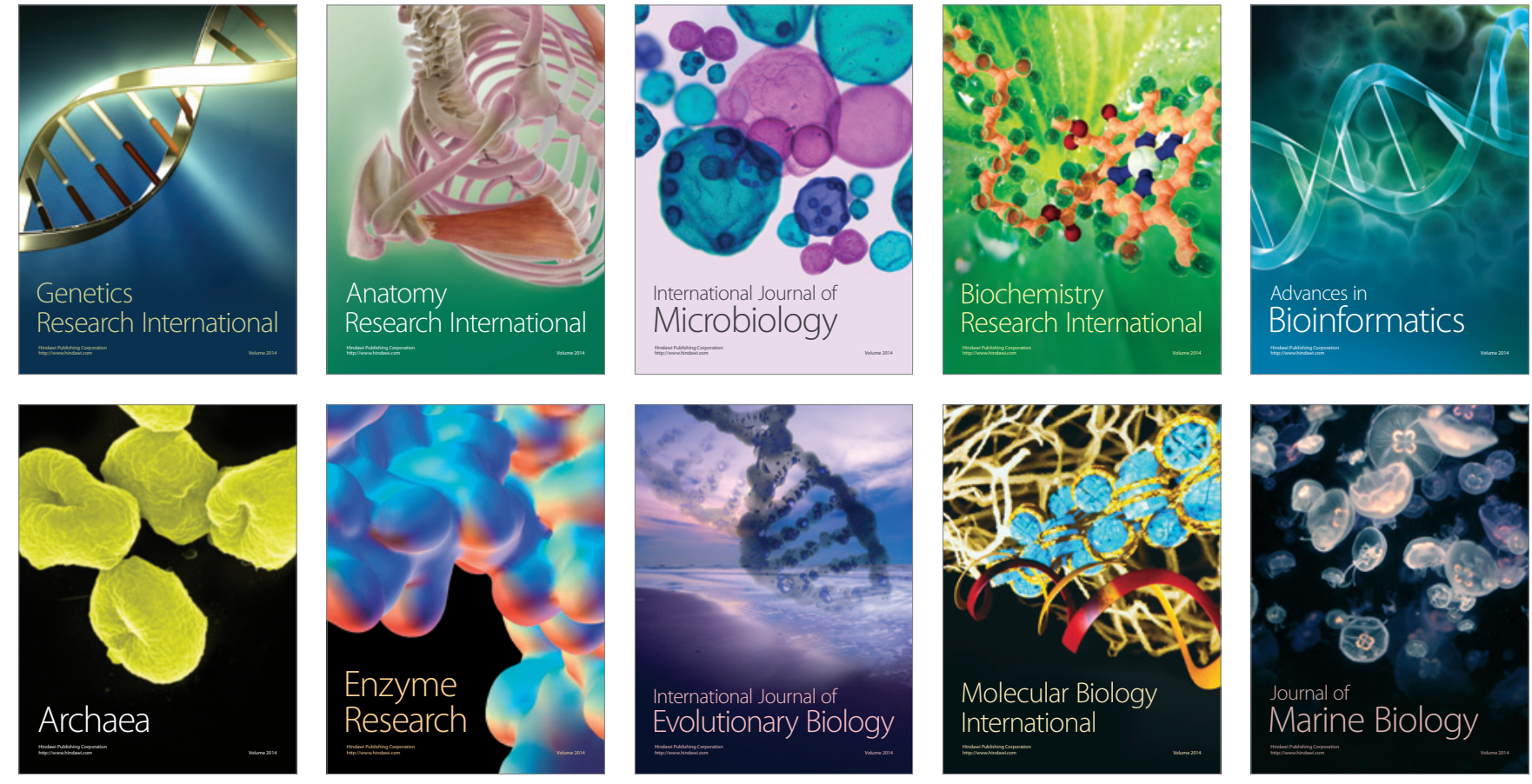